This item was submitted to Loughborough's Research Repository by the author.

Items in Figshare are protected by copyright, with all rights reserved, unless otherwise indicated.

Police efficiency in offences cleared: an analysis of English 'basic command units'

PLEASE CITE THE PUBLISHED VERSION

LICENCE

CC BY-NC-ND 4.0

REPOSITORY RECORD

Drake, Leigh M., and Richard Simper. 2019. "Police Efficiency in Offences Cleared: An Analysis of English 'basic Command Units'". figshare. https://hdl.handle.net/2134/366. 
This item was submitted to Loughborough's Institutional Repository by the author and is made available under the following Creative Commons Licence conditions.

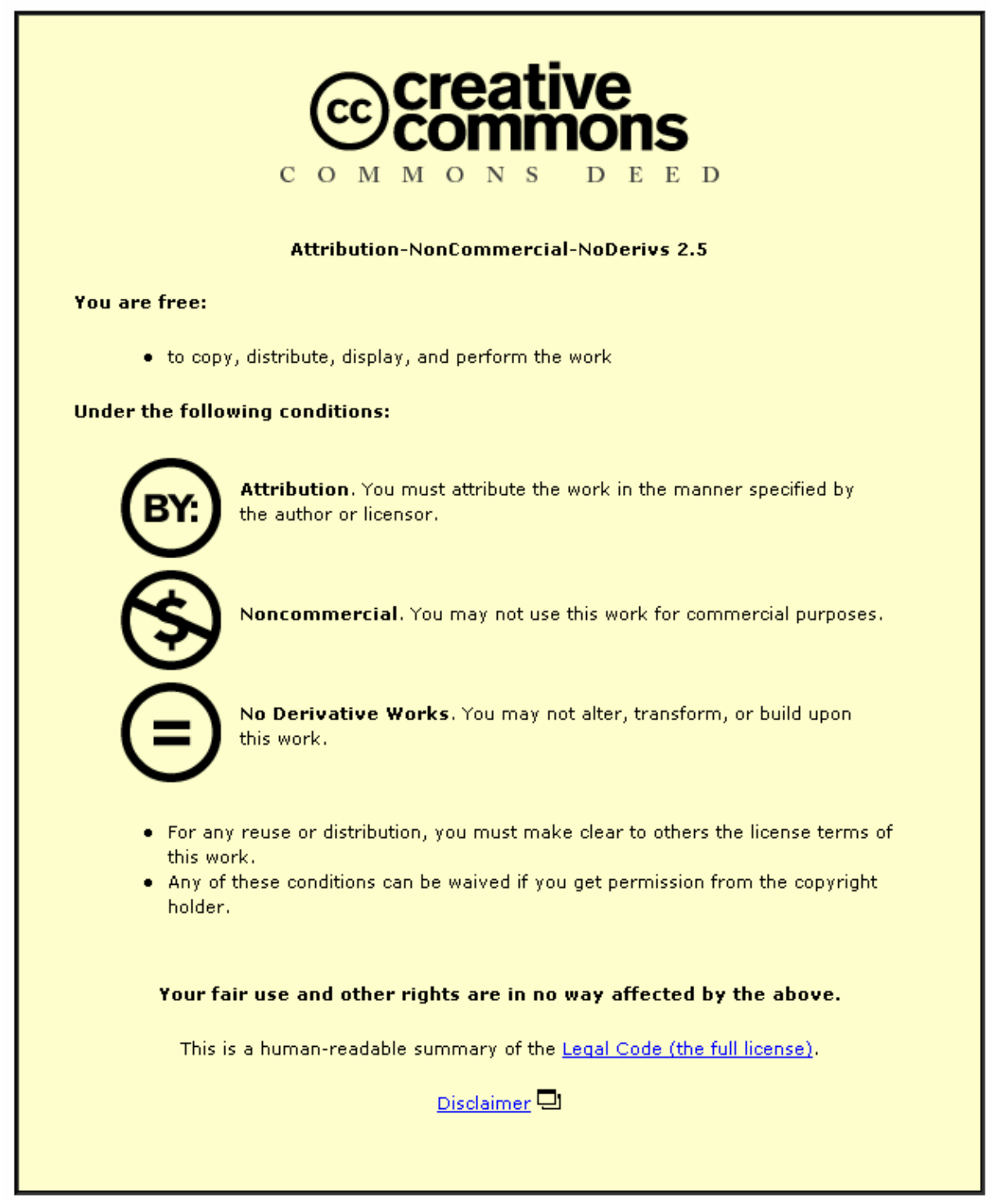

For the full text of this licence, please go to: http://creativecommons.org/licenses/by-nc-nd/2.5/ 


\title{
Police Efficiency in Offences Cleared: An Analysis of English 'Basic Command Units'.
}

\author{
LEIGH DRAKE AND RICHARD SIMPER \\ Department of Economics, Loughborough University, Loughborough, LE11 3TU, \\ England,E-mail: L.M.Drake@lboro.ac.uk and R.Simper@lboro.ac.uk
}

\begin{abstract}
The job of policing covers a wide range of activities including, traditional crime detection and punishment, and the non-traditional aspects such as community meetings. However, the major focus of policing is on crime detection and prevention. This paper specifically considers these functions with respect to Basic Command Units (BCUs) or 'precincts', and determines their relative efficiency in this key area using DEA and the little used stochastic distance frontier. Relative Efficiency is measured in the context of a 'pure production approach' relating the incidence of various crimes (inputs) to the corresponding clear offences (outputs). This type of efficiency ranking can also help in further analysing best practice in order to reduce crime and the fear of crime in many police forces. The powerful non-linearity established in this relationship has important implications for police resourcing and funding as highlighted by Houpis et al (2001)
\end{abstract}

Keywords: data envelopment analysis, stochastic output distance frontier, police efficiency JEL: C22, H0,K0 


\section{Introduction}

Since Becker's (1968) seminal paper on the deterrence/prevention hypothesis of crime, economists have considered how governments can reduce the incidence of criminal activities in cities, districts and towns. This analysis initially focused on a set of policy objectives based on the economic-sociological theories of criminal behaviour, but has now recently been refocused on the increasing costs of crime and policing. For example, in the US, the cost of crime to victims has been estimated at over \$200 billion per year (Miller et al (1993)) and in the UK at $£ 60$ billion ( $\$ 90$ billion) per year for victims and in the running the criminal justice system (Home Office (2000)). With respect to policing, over the last ten years US expenditure on policing has increased from over \$36 billion to \$65 billion in 2001 (Bureau of Justice Statistics) and English and Welsh police force expenditure has increased from $£ 6$ billion ( $\$ 9$ billion) to over $£ 9$ billion ( $\$ 13.5$ billion) in 2001 (Home Office Statistics).

In the UK, however, the increase in police funding has not led to a proportionate decrease in national crime rates. This contrasts with the US which has seen considerable decreases in crimes committed (reported) in recent years. The FBI 'Crime Index Total', for example, decreased from 13,989,543 in 1994 to 11,605,751 in 2000, whereas total crime recorded in the UK increased from 5,100,241 to 5,252,980 during the same period (Home Office Criminal Statistics). Hence, this failure to reduce crime despite extra funding has been linked to the new efficiency drive instigated by the UK Government. Furthermore, as the crime rate appeared to rise with the economic cycle, contrary to many economic theories, commentators began to question the effectiveness of the English and Welsh police forces. Stephens (1994), for example, has identified the growing cost of, and increasing levels of crime, coupled with the declining public standing of the police force (associated with, miscarriages of justice such as the Guildford Four and the Birmingham Six, and the miners' strike in 1984/85, ) as a major impetus in the re-evaluation of police functions.

These factors led to an inspection and review of English and Welsh police forces, firstly under the 1979 Thatcher Conservative government. Since being elected in 1997, however, the new Labour government has carried on this agenda of promoting efficiency in the police force (see the Home Office Inspectorate of Constabulary (HMIC) (1998) report "What Price Policing"). The report reiterated the previous Conservative government's efficiency drive in the police service with the 
HMIC arguing that, "police managers need to work harder to ensure that Value For Money (VFM) is achieved, for competitive pressure has to be created internally. The costing of activity with subsequent measurement and comparison of performance provide the means by which such encouragement is given" (para. 10). Finally, in the analysis of police efficiency and its measurement the UK Government recently commissioned a report "Improving Police Performance" by the Public Services Productivity Panel (PSPP) (2000) ${ }^{1}$. The PSPP Report stated that "efficiency is a measure of the police's performance in meeting their overarching aims and objectives for the money spent." (page 4) and argued that the nonparametric Data Envelopment Analysis (DEA) and the parametric Stochastic Frontier Analysis (SFA) be utilised to estimate a ranking of best to worst police forces (for an example see Drake and Simper (2001)).

The desire to measure the efficiency of public services and especially police forces, is just not related to the UK experience. Many national governments have set up agencies, departments and institutes, and enacted legislation in order to consider how policing performance can be assessed and to enable benchmarking. Forerunners to the current changes in assessing public service efficiency in the UK can be seen, inter alia, in the US Government Performance and Results Act 1993 and changes in policing in Australia and Canada. In the former case, the New York Police Department has been studied extensively in terms of their ability to reduce the level of crime, due to their successful introduction of CompStat. This was hailed as a system that "at the core of it is the principle of accountability. Holding the people who run the precincts accountable for achieving what the public wants them to do, which is reduce crime." (page. 9, Mayor Rudolph Giuliani quoted in O'Connell (2001)). In addition, the policing function has come under scrutiny in Australia, where policing has moved to an outputs objective budgeting approach in order to enable performance reviews (SCRCSSP (2000)). Finally, The Royal Canadian Mounted Police (RCMP) aim for "continuing efforts to develop sound performance indicators as part of government-wide efforts to demonstrate value for money and accountability." Page. 14. (RCMP Report 2000).

\footnotetext{
${ }^{1}$ Both authors of this study were advisors over a 2 year period to H. M. Treasury and Home Office on the issues of estimating police efficiency, resulting in recommendations outlined in the PSPP (2000) report.
} 
Hence, the need to assess the policing function has been deemed an important aspect of determining the allocation of scarce resources in government budgets around the world (for a review of UK policing see Drake and Simper (2002)). There are however, difficulties in modelling the policing function, especially as some activities are not measurable, for example, walking the beat. This has led economists to posit two methodologies, the cost and the production approach. The former relates inputs/costs to possible outputs/outcomes (such as crime clear up rates): see early cost function estimation of US policing by Darrough and Heineke (1979), GyimahBrempong (1987) and more recently Nyhan and Martin (1999); and for the UK, Cameron (1989), Drake and Simper (2000 and 2001). The latter methodology relates the number of crimes committed to the effectiveness of forces in clearing up those crime: see Thanassoulis (1995) for a UK example, Sun (2002) for a Taiwanese example, and finally Diez-Ticio and Mancebon (2002) for an example of the production approach utilised to assess the efficiency of Spanish policing.

This paper utilises a 'pure' production methodology in which we aim to rank Basic Command Units on their ability to clear up various acts of crime, and hence to deter future criminal activity. The innovation to the literature is that we utilise a sample of Basic Command Units (BCUs), or precincts, from English police forces, and to the authors knowledge this is the first such work on UK policing. In addition, we estimate and compare two techniques, the nonparametric Data Envelopment Analysis (DEA), and the little used parametric Stochastic Output Distance Frontier (SODF). The paper is structured as follows. In Section II we discuss the methodology associated with modelling policing and present the nonparametric and parametric models utilised to estimate efficiency. The data and variables utilised are presented in Section III; Section IV discusses the results; and we conclude with Section 5 .

\section{Estimation Models and Data}

\section{II.i. Parametric Efficiency Analysis}

Given that the aim of policing is to maximise the clear up rates of crime at Basic Command Unit (BCU) level, we can write each BCU's direct production function as 


$$
\mathrm{F}(\mathrm{x}) \underset{\mathrm{y}}{\equiv} \max \{\mathrm{y} \mid(\mathrm{y}, \mathrm{x}) \text { feasible }\}
$$

where $\mathrm{y}$ is a vector of outputs and $\mathrm{x}$ is a vector of inputs. In the literature, it is then usual to specify a production and/or cost function with a stochastic error appended to the function. However, the stochastic production frontier approach has the disadvantage that, as output is the dependent variable, only a single output production process can be modelled. This is clearly not appropriate in policing as police forces deliver a range of services or outcomes. Furthermore, it would be very difficult to construct an appropriate composite output (outcome) measure.

The usual solution to this problem in empirical applications is to make use of the duality between cost and production functions and to specify and estimate a stochastic cost frontier. This permits the modelling of a multi-input, multi-output

production process. A particular drawback in utilising a cost function specification to model public sector services such as policing, however, is that this requires data on total costs, outputs and input prices. While the latter are generally available for some inputs such as labour (staff), they are typically not available for capital inputs as this requires data on both capital expenditure and the units of capital utilised (see Drake and Simper (2000)). A further potential drawback of the stochastic cost frontier approach is that any non-random deviations above the cost frontier will be associated with both allocative and technical inefficiency. In contrast, the relative efficiency measures derived from the non-parametric methodologies such as DEA typically relate only to technical efficiency. Hence, the relative efficiency measures derived from parametric and non-parametric approaches are often not directly comparable.

\section{II.ii. Stochastic Output Distance Frontier (SODF).}

A potential solution to these problems, but one that has not been widely used empirically, it to employ a parametric approach, but to specify and estimate a stochastic distance frontier rather than a stochastic cost or production frontier. The distance function specification has the advantages of permitting the modelling of a multi-input, multi-output production process, and being a function only of outputs and 
inputs. Hence, the distance function does not require data on input prices. Furthermore, as it is a function of outputs and inputs, the stochastic distance frontier produces a relative efficiency measure that is directly comparable to the measure of technical efficiency produced by DEA, which is a non-parametric distance function technique. For an introduction to the distance function concept see Cornes (1992), and for an empirical application see Coelli and Perlman (1999). The output distance function estimated can be written as follows, where $\mathrm{y}$ is output and $\mathrm{x}$ are inputs,

$$
\mathrm{D}_{\mathrm{O}}(\mathrm{x}, \mathrm{y})=\min \{\theta \mid \mathrm{y} / \theta \in \mathrm{F}(\mathrm{x})\}
$$

The output oriented distance function can be interpreted as the greatest radial expansion of the output vector, with the input vector held fixed. The distance function $\mathrm{D}_{\mathrm{O}}(\mathrm{x}, \mathrm{y})$ will take a value which is less than or equal to one hundred, whereby if it less than one hundred a radial expansion of $1 / \theta$ is needed to reach the frontier.

In this paper we employ the popular Translog flexible functional form, where the output distance function with 6 outputs and 6 inputs can be expressed as:

$$
\begin{aligned}
\ln \mathrm{D}_{\mathrm{Oi}}= & \text { const }+\sum_{\mathrm{i}=1}^{6} \alpha_{\mathrm{i}} \ln \mathrm{y}_{\mathrm{i}}+\frac{1}{2} \sum_{\mathrm{i}=1}^{6} \sum_{\mathrm{j}=1}^{6} \sigma_{\mathrm{ij}} \ln \mathrm{y}_{\mathrm{i}} \ln \mathrm{y}_{\mathrm{j}}+\sum_{\mathrm{m}=1}^{6} \beta_{\mathrm{m}} \ln \mathrm{x}_{\mathrm{m}} \\
& +\frac{1}{2} \sum_{\mathrm{m}=1}^{6} \sum_{\mathrm{n}=1}^{6} \gamma_{\mathrm{mn}} \ln \mathrm{x}_{\mathrm{m}} \ln \mathrm{x}_{\mathrm{n}}+\frac{1}{2} \sum_{\mathrm{i}=1}^{6} \sum_{\mathrm{m}=1}^{6} \delta_{\mathrm{im}} \ln \mathrm{y}_{\mathrm{i}} \ln \mathrm{x}_{\mathrm{m}}+\ln \varepsilon_{\mathrm{i}}
\end{aligned}
$$

Young's theorem requires that the second order parameters of the distance function must be symmetric, that is, $\sigma_{i j}=\sigma_{j i}$ for all $\mathrm{i}, \mathrm{j}$, and $\gamma_{m n}=\gamma_{n m}$ for all $\mathrm{m}, \mathrm{n}$. Finally, homogeneity of degree 1 in outputs requires the following restrictions, $\sum_{i=1}^{6} \alpha_{i}=1$, $\sum_{\mathrm{j}=1}^{6} \sigma_{\mathrm{j}}=0$, and $\sum_{\mathrm{m}=1}^{6} \delta_{\mathrm{im}}=0$.

A convenient method of imposing homogeneity upon the Translog distance function is to follow Lovell et al (1994) and observe that homogeneity implies that: 


$$
\mathrm{D}_{\mathrm{O}}(\mathrm{x}, \omega \mathrm{y})=\omega \mathrm{D}_{\mathrm{O}}(\mathrm{x}, \mathrm{y}) \text { for any } \omega \succ 0
$$

Hence, if we arbitrarily choose the $\mathrm{k}^{\text {th }}$ output, and set $\omega=1 / \mathrm{y}_{\mathrm{k}}$ then, using TL( . ) to represent the Translog function, we can express the output distance function as:

$$
\begin{array}{r}
\ln \left(\mathrm{D}_{\mathrm{Oi}} / \mathrm{y}_{\mathrm{k}}\right)=\mathrm{TL}\left(\mathrm{x}_{\mathrm{i}}, \mathrm{y}_{\mathrm{i}} / \mathrm{y}_{\mathrm{k}}, \text { const }, \alpha, \sigma, \beta, \gamma, \delta\right) \\
\mathrm{i}=1,2, \ldots, \mathrm{N}
\end{array}
$$

or $\quad \ln \mathrm{D}_{\mathrm{Oi}}-\ln \left(\mathrm{y}_{\mathrm{k}}\right)=\mathrm{TL}\left(\mathrm{y}_{\mathrm{i}} / \mathrm{y}_{\mathrm{k}}, \mathrm{x}_{\mathrm{i}}\right.$, const $\left., \alpha, \beta, \gamma, \delta\right)$

$$
\mathrm{i}=1,2, \ldots, \mathrm{N}
$$

It follows that we can re-write this Translog distance function as:

$$
\begin{array}{r}
-\ln \left(\mathrm{y}_{\mathrm{k}}\right)=\mathrm{TL}\left(\mathrm{x}_{\mathrm{i}}, \mathrm{y}_{\mathrm{i}} / \mathrm{y}_{\mathrm{k}}, \alpha, \sigma, \beta, \gamma, \delta\right)-\ln \left(\mathrm{D}_{\mathrm{Oi}}\right) \\
\quad \mathrm{i}=1,2, \ldots, \mathrm{N}
\end{array}
$$

Hence, if we append a symmetric error term, $v_{i}$ to account for statistical noise, and rewrite $\ln \left(\mathrm{D}_{\mathrm{Oi}}\right)$ as $\mu_{i}$, we can obtain the stochastic output distance function, with the usual composite error term, $\varepsilon_{\mathrm{i}}=\mathrm{v}_{\mathrm{i}}-\mu_{\mathrm{i}}$.

$$
\begin{array}{r}
\ln \left(\mathrm{y}_{\mathrm{k}}\right)=-\mathrm{TL}\left(\mathrm{x}_{\mathrm{i}}, \mathrm{y}_{\mathrm{i}} / \mathrm{y}_{\mathrm{k}}, \alpha, \sigma, \beta, \gamma, \delta\right)+v_{\mathrm{i}}-\mu_{\mathrm{i}} \\
\quad \mathrm{i}=1,2, \ldots, \mathrm{N}
\end{array}
$$

We make the standard assumptions that the $v_{i}$ are normally distributed random variables while the $\mu_{i}$ are assumed to have a truncated normal distribution.

As is usual in the stochastic frontier approach, the predicted value of the output distance function for the $\mathrm{i}^{\text {th }}$ firm, $\mathrm{D}_{\mathrm{Oi}}=\exp \left(-\mu_{\mathrm{i}}\right)$, is not directly observable, but must be derived from the composed error term, $\varepsilon_{i}$. Hence, predictions for $\mathrm{D}_{\mathrm{Oi}}$ 
are obtained using Coelli's Frontier 4.1 programme, based on the conditional expectation: ${ }^{2}$

$$
\mathrm{D}_{\mathrm{Oi}}=\mathrm{E}\left[\left(-\mu_{\mathrm{i}}\right) \mid \varepsilon_{\mathrm{i}}\right]
$$

\section{II.iii. Data Envelopment Analysis (DEA)}

The non-parametric efficiency approach was originally developed by Farrell (1957) and later elaborated by Banker, Charnes and Cooper (1984) and Fare, Grosskopf and Lovell (1985). The constructed relative efficiency frontiers are non-statistical or nonparametric in the sense that they are constructed through the envelopment of the decision making units (DMUs) with the "best practice" DMUs forming the nonparametric frontier. This non-parametric technique was referred to as Data Envelopment Analysis (DEA) by Charnes, Cooper and Rhodes (1978).

A particular advantage of non-parametric techniques such as DEA, relative to statistical or parametric techniques such as stochastic frontier analysis (see Drake and Weyman-Jones (1996) and Ferrier and Lovell (1990)), is that the latter must assume a particular functional form which characterises the relevant economic production function, cost function, or distance function. Hence, any resultant efficiency scores will be partially dependent on how accurately the chosen functional form represents the true production relationship (i.e., the relationship between inputs/resources and outputs). As DEA is non-parametric and envelops the input/output data of the DMUs under consideration, the derived efficiency results do not suffer from this problem of functional form dependency. Examples of DEA applied to the analysis of police efficiency include, Thanassoulis (1995), Drake and Simper (2000) for the UK, and Carrington et al (1997) for New South Wales.

For each DMU in turn, using $\mathrm{x}$ and $\mathrm{y}$, to represent its particular observed inputs and outputs, pure technical efficiency is calculated by solving the following output based linear programme

\footnotetext{
2 Given the transformation in equation (8) the production function procedure is used to obtain the correct efficiency scores for an output distance function using Frontier 4.1.
} 
Choose $\{\theta, \lambda\}$ to: $\min \theta$ such that: $\quad \lambda^{\prime} \mathrm{Y} \geq \mathrm{y} / \theta$

$$
\begin{array}{r}
\lambda^{\prime} \mathrm{X} \leq \mathrm{x} \\
\lambda_{\mathrm{i}} \geq 0, \Sigma \lambda_{\mathrm{i}}=1, \mathrm{i}=1, \ldots, \mathrm{n}
\end{array}
$$

Hence, in (9) we assume a variable returns to scale reference technology and concentrate exclusively on technical efficiency, i.e., the efficiency of translating inputs into outputs at the given scale of production. Due to the difficulties in accurately measuring all input prices in public sector services such as the police force, this paper does not consider allocative efficiency.

\section{The Data and Variable Descriptions}

The availability of data at Basic Command Unit (BCU) level is a recent Home Office initiative, which many see as a forerunner to ranking the BCUs instead of the 43 police forces (see Drake and Simper (2001)). The first data set published by the Home Office is utilised in this study and compares the six main crime categories to offences cleared (clear up rates - UK terminology) for a sample of 293 BCUs from 38 forces from 2001/02 (we have excluded the City of London and airports, the former due to the small size of the BCUs and the later due to the fact that airport BCUs have more diverse crime and management operations than normal BCUs). The variables that are published by the Home Office can be split into 6 inputs and 6 outputs in accordance with a 'pure' production approach of modelling police efficiency.

As discussed above the production approach in this study follows Thanassoulis (1995), Diez-Ticio and Mancebon (2002) and Sun (2002). In the former, utilising English and Welsh police force data, a DEA output based specification was modelled with inputs including violent crimes, burglaries, other crimes and the number of officers, and outputs including violent crime offences cleared (clear ups), burglary clear ups, and other crime clear ups. This is also the format for Sun (2002) in a model of Taipei Municipal Police Departments. Finally, Diez-Ticio et al (2002) use population and number of vehicles as possible additional influences on police efficiency scores. Due to the unavailability of data on police 
officer numbers at BCU level, we have advanced the 'pure' production approach relating crime clear ups to incidences of crime. ${ }^{3}$

In this study, therefore, the inputs are number of crimes committed where; X1 is violent crimes against persons; X2 is sexual offences; X3 is Robbery; X4 is Burglary of dwelling; X5 is theft of a motor vehicle; and X6 is theft from a vehicle. The outputs are the corresponding number of offences cleared (cleared up crimes), for example, Y1 is the number of violent crimes against the person cleared up, etc., The descriptive statistics of the input and output variables utilised in this study are presented in Table 1.

\section{INSERT TABLE 1}

An analysis of the data shows wide variations in BCU crimes and clearups primarily linked to their geographic position, that is whether they are city or rural based. For example, in terms of population size, the smallest BCU is Newcastle Central with a population of 4,211, while the second smallest, Birmingham City Centre has a population of 12,746 . In contrast, the largest BCU in the sample is Croydon with a population of 319,185 . However, population size does not appear to be highly correlated with the number of offences. For example, in terms of the input X1, violence against the person, Newcastle Central recorded 996 and Birmingham City Centre 2554 offences, whereas Croydon (London) recorded 6059 and Southern ( $4^{\text {th }}$ largest BCU with 309,548 population) 1,344 offences. ${ }^{4}$ In terms of offences cleared (clear ups), if we consider output Y1, violence against the person, South Manchester (population 298,558 $-6^{\text {th }}$ largest) cleared the most crimes at 3,756 but the second placed North Manchester (population 139,994 - 186 ${ }^{\text {th }}$ largest) cleared 3362 offences.

\footnotetext{
3 While it would be desirable to include the number of police officers as an input were the data available, it should be noted that the Police Funding Formula (PFF) is designed to ensure that police force BCUs are adequately resourced.

4 English and Welsh police forces are funded through a Police Funding Formula which takes account of demographic, geographic and sociographic factors in the allocation of monies to forces through a regression equation. That is, forces budgets are affected by whether they are inner-city, have high unemployment, high population density, etc., in their ability to reduce the level of crime within that area, see Home Office (1998).
} 


\section{Results and Discussion}

\section{IV.i Technical Efficiency}

Table 2 presents summary statistics across the BCUs in each police force in terms of both the DEA and Stochastic Output Distance Frontier (SODF) efficiency results. ${ }^{5}$ The Avon and Somerset force, for example, has 8 BCUs and their SODF efficiency score ranged from 63.00 to 86.35 , with a mean of 75.21 (all BCU results are presented in the Appendix). The results reveal a very wide range of efficiency scores across police force BCUs. In terms of the mean PTE efficiency scores in Table 2, for example, these range from 100 for forces such as Derbyshire, Cumbria, Northamptonshire, and North Yorkshire to 73.36 for the Metropolitan. As would be expected, the mean SODF efficiency levels are somewhat lower than the PTE means as the former technique typically accords units an efficiency score of less than 100 . In contrast, when using DEA it is often the case that many units are deemed to be on the efficient frontier and therefore exhibit a PTE score of 100. Hence, the mean SODF scores range from 95.34 for the Gloucestershire force down to only 67.44 for the Staffordshire.

\section{INSERT TABLE 2}

It is clear from these results, therefore, that some police forces display a consistently high level of efficiency across their BCUs, while other forces display both lower average levels of BCU efficiency and a greater range of efficiency levels. This is most evident by contrasting the maximum (Max) and minimum (Min) efficiency scores with the mean levels. If we take the case of the North Yorkshire force, for example, all of its BCUs exhibit PTE scores of 100 while the mean SODF score of 95.16 reflects a range of efficiency scores between 99.39 and 86.79. In contrast, the Metropolitan Police Force (London) exhibits a mean PTE score of 73.36 and a Max and Min of 100 and 43.86 respectively. The corresponding mean SODF score is 74.75 with a max and min of 99.57 and 45.14. Similarly, the Hertfordshire

\footnotetext{
5 The Log-Likelihood Ratio to test for a one sided error was equal to 78.58 significant at the $1 \%$ critical level.
} 
has a mean PTE score of 86.36 with scores ranging from 100 to 46.24 . These marked disparities in efficiency levels across BCUs within the same police force is illustrated very clearly in Figure 1, for the SODF scores, and in Figure 2 for the PTE scores.

\section{INSERT FIGURE 1}

\section{INSERT FIGURE 2}

With respect to Figure 1, this indicates that relatively few police forces have all their BCUs clustered close to the $100 \%$ efficiency level. Furthermore, Figure 2 also indicates very clearly that there are a number of forces which not only have relatively low mean SODF efficiency levels, but also have no BCUs which exhibit relatively high efficiency levels. In other words the performance of these police forces is consistently poor across all BCUs. Obvious examples include force 29, the Staffordshire, with a mean score of 67.44, and efficiency levels ranging between 77.45 and 52.49. Similarly, force number 31, the Surrey, exhibits a mean efficiency score of 67.98 , a min of 45.99 and a maximum of only 80.64 .

In summary, therefore, these results suggest that, for many forces, considerable benefit could be gained by the poorer performing BCUs learning from, and sharing the best practices of their better performing BCUs. For other forces with generally poor performances across all their BCUs, however, more benefit would be gained by examining the best practice of the more efficient BCUs in other forces. Obvious benchmark forces in these cases would be the forces in which the BCUs consistently exhibit a relatively high level of efficiency compared to the BCUs in other forces. For police forces generally, however, the results clearly indicate that, in many cases, forces could improve their overall efficiency by raising the levels of efficiency of their poorest performing BCUs towards the levels exhibited by their best performing BCUs.

\section{INSERT TABLE 3}

Table 3 provides details of the top 20 and bottom 20 performing BCUs according to the SODF scores. We elect to use the SODF scores in this instance as DEA tends to produce many BCUs which are jointly ranked at 100 according to the 
PTE scores. The best performing BCU is the Easington unit of the Durham Constabulary with an SODF score of 99.99, while the worst performing BCU is the Broxbourne unit of the Hertfordshire force with an efficiency score of only 39.21. With respect to the point made previously, that a number of forces have BCUs which display both very good and very poor performance, it is interesting to note that the Metropolitan Police Force has 3 units in the top 20, but no less than 10 units in the bottom 20. Similarly, the West Yorkshire force has a BCU (Dewsbury, rank $4^{\text {th }}$, 99.85) in the Top 20, but also a BCU (Weetwood, rank 285 ${ }^{\text {th }}, 59.76$ ) in the bottom 20. Hence, these are clear examples of forces where there would be considerable merit in making a detailed investigation into the operating procedures of their best and worst performing BCUs, with a view to raising the efficiency levels of the latter and thereby improving the performance of the police force overall.

\section{INSERT FIGURE 3}

Due to the well established pros and cons of the non-parametric technique, DEA, and the parametric stochastic frontier technique, the recent PSPP (2000) report advocated the joint use of these techniques in assessing the relative efficiency of police forces. In order to make the results as comparable as possible, we chose to utilize the stochastic distance frontier approach, as opposed to the stochastic cost frontier approach advocated in PSPP (2000), as it is the parametric analogue of DEA which is a non-parametric distance function technique. The contrast between the two sets of efficiency results, PTE and SODF, is illustrated in Figure 3. While there is clearly a strong positive correlation between the two efficiency measures (rank correlation 0.536 , significant at the $1 \%$ level), which provides some cross validation for the two approaches, there are also some outliers. It is clear, for example, that of the large number of BCUs ranked at 100 by DEA, the corresponding SODF scores range from 99.99 to 59.76 (see Appendix 1). Conversely, there are BCUs which are rated as highly efficient according to SODF, but exhibit a relatively low PTE score. The Hounslow (Metropolitan), for example, has an SODF score of 97.17, but a PTE score of only 62.98. While such cases tend to be the exception, they suggest the need for further investigation in order to establish the causes of the differential efficiency scores. They also indicate the dangers in relying on one efficiency measurement technique in isolation. 


\section{IV.ii The Size Efficiency Relationship in Policing at the BCU level}

It is potentially very informative to analyse the possible relationship between size and efficiency in policing at the BCU level. With respect to technical efficiency, this amounts to establishing, for example, whether larger BCUs tend to be more, or less, efficient than their smaller counterparts. As emphasized previously, we have applied a 'pure' production approach in which police force BCU efficiency is assessed in terms of their ability to translate recorded crimes into cleared-up crimes, without the specification of any economic inputs/costs such as labour, capital, etc. Hence, a natural measure of BCU size in this context is the total number of recorded crime incidents, i.e., the summation of inputs X1 to X6. With this type of size specification, it is possible to hypothesise some alternative relationships between size and technical efficiency. One possibility is a form of "learning by doing effect" in which those BCUs which experience higher incidences of recorded crime become more adept at solving those crimes. This would suggest a positive correlation between size, as proxied by total recorded crimes, and technical efficiency. Alternatively, one might hypothesise that there might be a "swamping effect" in which the sheer volume of crimes with which the BCUs have to deal has a detrimental effect on their ability to solve or clear-up these crimes. Clearly, this would imply a negative relationship between size and technical efficiency.

\section{INSERT FIGURE 4}

In the interests of brevity we illustrate the size - DEA technical efficiency relationship in terms of the scatter plot in Figure 4. Although there is clearly a concentration of the efficient units at the low to moderate crime levels (below 9000 incidents), this reflects the frequency distribution of total crimes across BCUs, rather than any underlying efficiency effect. Indeed, it is quite clear that there are a large number of technically efficient BCUs right across the size spectrum up to BCUs experiencing total crime incidents of almost 26000. Furthermore, it is clear from the scatter diagram that there is no apparent size-efficiency relationship, either positive or negative. 
Although there is no apparent relationship between size and technical efficiency, it must be recognized that the latter scores are derived under the assumption of variable returns to scale. In other words this form of DEA efficiency analysis specifically allows for the possibility that there may be scale effects in respect of clearing-up crimes. Hence, in order to examine this type of size-efficiency relationship, i.e., the presence of either increasing or decreasing returns to scale, we must examine the DEA scale efficiency results. These are obtained by solving the linear programme (9) under the assumption of constant returns to scale (OE) rather than variable (PTE), i.e., without the constraint that $\Sigma \lambda_{i}=1$. The ratio of the two sets of DEA efficiency measures then gives us a measure of scale efficiency: $\mathrm{SE}=\mathrm{OE} /$ PTE. In order to establish the nature of the returns to scale, for those BCUs which are not scale efficient $(\mathrm{SE}<100)$, we run the linear programme $(9)$ once more under the constraint of non-increasing returns to scale. Any disparity between the two sets of technical efficiency scores indicates the presence of increasing returns to scale (IRS), while consistency between the results indicates decreasing returns to scale (DRS).

In the interests of brevity the full set of scale efficiency results are not presented (a full set of results are available from the authors on request). Interestingly, however, out of a total of 293 BCUs, no less than 192 exhibited DRS, with 88 BCUs exhibiting constant returns to scale (CRS) and only 13 exhibiting IRS. Furthermore, out of those 13 BCUs, the majority exhibited SE scores were close to 100 , i.e. above 99.5, with only 2 recording SE scores below 98 (93.46, 96.45). Hence, BCUs in England appear to be dominated by DRS in respect of clearing-up crimes, with very little evidence of IRS.

\section{INSERT FIGURE 5}

The relationship between the DEA scale efficiency scores and size is illustrated in Figure 5. Not surprisingly, given the predominance of BCUs exhibiting DRS, this indicates a very clear negative relationship between SE and size, as proxied by the total incidents of crime. The scale efficient BCU's are generally concentrated at total crime levels below 10000, with only one scale efficient BCU at crime levels above 10500. In contrast, the two forces with the largest incidences of crime, Lambeth (Metropolitan) and South Manchester (Manchester), have SE scores of 62.28 and 
77.88 respectively. A further indication of the powerful scale economies which appear to operate in clearing-up crimes at the BCU level is the fact that the largest 15 BCUs (ranked by total crime incidents) have a mean SE score of only 73.13, whereas the smallest 15 have a mean SE score of 99.71.

With respect to possible explanations for the powerful negative relationship between SE and total crimes, and for the prevalence of DRS at the BCU level, the most likely explanation relates to the non-linearity of the relationship between the levels of crime and the resources required to fight those crimes. This problem has been increasingly recognized in recent years (see, for example, Houpis et al, (2001)) and has been exacerbated since $1995 / 96$ by the introduction of the Police Funding Formula (PFF). In the key area of crime management, for example, the so-called workload factors such as personal crime incidents are related to a range of specific drivers such as unemployment rate, population density, owner occupation rate, etc. The technique used to establish the relationship between these key drivers and the workload factors is typically a basic regression analysis. Hence, this approach assumes a linear relationship between these key drivers and crime incidents, but more crucially, as the regression analysis is used to generate workload factors, it also implicitly assumes a linear relationship between the incidents of crime and the workload (resources) required to deal with these crimes.

This problem has been highlighted by Houpis et al (2001) in the context of the largest police force in England, the Metropolitan Police Force. They argue that, not only has the proportion of funding going to the Metropolitan declined significantly since the introduction of the PFF, but that non-linearity in the relationship between crime and crime fighting resources implies that some areas (BCUs) in London are disadvantaged by the use of average values for the key crime drivers across the whole of London. They state that:

"If the relationship between the levels of crime and the resources required to detect and deal with it were linear (i.e., double the level of crime required double the level of resources) then aggregating laveraging across London to derive the formula created no bias. If, however, the relationship were non-linear, so that the higher levels of crime imply a higher cost/crime for detecting and dealing with it, then averaging across London could lead to a significant underestimation of the real resources 
required to deal with the levels of crime reported in the capital - an area with double the number of crimes would face a 45\% higher cost per crime." (p. 34).

To the authors knowledge, this is one of the first pieces of research, using techniques such as DEA, to actually establish the presence of powerful non-linearities in the relationship between crime levels and crime offences cleared. Furthermore, in showing that there is no obvious relationship between technical efficiency and crime levels, we are able to show that we have identified a genuine scale effect in policing rather than a problem of lower efficiency levels in larger BCUs (defined in terms of total crime incidents).

While this is an interesting and important result in its own right, it also has important implications for the future. Specifically, the combination of non-linearity outlined above and the PFF suggests that BCUs and police forces characterized by relatively high levels of crime will become progressively more underfunded over time. This will inevitably reduce their ability to deal effectively with the levels of crime they face and may result in declines in technical efficiency over time in respect of clearing-up crimes. More worryingly, however, the socio-economic literature dating back to Becker (1968) suggests that criminals assess the probability of being caught prior to committing a crime. Hence, it is likely that any such decline in the efficiency of crime detection and solving is likely to lead to an increase in the actual incidents of crime with the possibility that criminals may elect to operate in areas (BCUs) where the probability of detection is perceived to be low. ${ }^{6}$

\section{Conclusion}

This paper is the first to employ both a parametric frontier distance function and nonparametric distance function approach to assess the relative efficiency of BCUs in English police forces. The results reveal considerable divergence in efficiency levels, both across police forces as a whole, and across BCUs within the same force. This

\footnotetext{
${ }^{6}$ Houpis et al (2001), for example, point out that: "The share of recorded crimes taking place in London has increased significantly during a period when overall crime levels have actually fallen”. (p. 27)
} 
suggests considerable scope for the sharing of best practices across BCUs in the same police force, and also between the best and worst performing forces.

The strong positive rank correlation between the PTE and the SODF efficiency scores provides a good degree of cross-validation for the two alternative techniques and suggests that they are both credible relative efficiency measures in respect of the assessment of police force and BCU relative efficiency. The presence of a number of outliers, however, suggests that it would be unwise to rely exclusively on one of these techniques in isolation. These results echo the previous results obtained in Drake and Simper (2002) in respect of English and Welsh police force efficiency. Further research is clearly required to establish the source of such discrepancies in the relative efficiency scores.

Finally, the DEA scale efficiency results reveal a powerful non-linear relationship between the level of crime and crime-clear-ups. This suggests that there is also a non-linear relationship between total crime incidents and the resources required to tackle and solve these crimes. This evidence, combined with the inherently linearity of the PFF implies that the BCUs with the highest crime levels may face a worsening under-funding in future years unless the PFF is fundamentally amended. In turn, this under-funding suggests the emergence of a potential vicious circle in which under-funding reduces the efficiency of the management of crime in the high crime BCUs, which then promotes an increase in criminal activity and worsens the under-funding, etc.

An important agenda for future research will be to analyse the presence of scale effects at both the police force level and the BCU level in order to provide further analysis of the resourcing requirements of police forces / BCUs and to cast some light on possible restructurings which could be undertaken at both police force and BCU level in order to enhance overall efficiency. 


\section{References}

Becker, G. (1968). “Crime and Punishment: An Economic Approach.” Journal of Political Economy. 76(2), 169-217.

Banker, R. D., Charnes, A., and Cooper, W. W. (1984). "Some Models for Estimating Technical and Scale Efficiencies in Data Envelopment Analysis." Management Science. 30, 1078-92.

Cameron, S. (1989). "Police Cost Function Estimates for England and Wales," Applied Economics, 21, 1279-1289.

Carrington, R., Puthucheary, N., Deirdre, R., and Yaisawarng, S. (1997) "Performance Measurement in Government Service Provision: The Case of Police Services in New South Wales.” Journal of Productivity Analysis. 8, 415-430.

Charnes, A., Cooper, W. W. and Rhoades, E. (1978). "Measuring the Efficiency of Decision Making Units.” European Journal of Operational Research. 2, 429-444.

Coelli, T., Perlman, S. (1999) “A Comparison of Parametric and Non-Parametric Distance Functions: With Application to European Railways." European Journal of Operational Research. 117, 326-339.

Cornes, T. (1992). Duality and Modern Economics. Cambridge University Press, Cambridge, UK.

Darrough, M. N. and J. M. Heineke. (1979). "Law Enforcement Agencies as Multiproduct Firms: An Econometric Investigation of Production Cost," Public Finance, 34, 176-195

Diez-Ticio, A. and Mancebon, M-J. (2002). "The Efficiency of the Spanish Police Service: An Application of the Multiactivity DEA Model." Applied Economics. 34, 351-362.

Drake, L. and Simper, R. (2002). "The Economics of Managerialism and the Drive for Value for Money in Policing: Best Value Performance Indicators vs. Efficiency Rankings,” Department of Economics, Loughborough University, Economic Research Paper No. 02/07.

Drake, L. and Simper, R. (2001). "Police Force Efficiency: Demonstration Project Peer Results (Home Office (2001))." Department of Economics, Loughborough University, Economic Research Paper No. 01/11. 
Drake, L. and Simper, R. (2000). "Productivity Estimation and the Size-Efficiency Relationship in English and Welsh Police Forces: An application of DEA and Multiple Discriminant Analysis." International Review of Law and Economics, 20, 53-73.

Drake, L. and Weyman-Jones, T. G. (1996). "Productive and Allocative Inefficiencies in U.K. Building Societies: A Comparison of Non-Parametric and Stochastic Frontier Techniques, Manchester School of Economic and Social Studies, 114, 22-37.

Fare, R., Grosskopf, S., and Lovell, C. A. K. (1985). The measurement in efficiency production, Kluwer Nijhoff, Boston, Mass.

Farrell, M. J. (1957). "The Measurement of Productive Efficiency." Journal of the Royal Statistical Association Series A, (CXX), 253-281.

Ferrier, G. D., Lovell, C. A. K., (1990), "Measuring Cost efficiency in Banking: Econometric and Linear Programming Evidence." Journal of Econometrics, 46, 229-245.

Gyimah-Brempong, K. (1987). "Economies of Scale in Municipal Police Departments: The Case of Florida." The Review of Economics and Statistics, 352-356.

Her Majesty's Inspectorate of Constabulary (HMIC). (1998), What Price Policing,. HMSO, London, UK.

Home Office. (1998). Formula for Police Specific Grant and Police Standard Spending Assessment in 1999/2000, HMSO, London, UK.

Home Office. (2000). The Cost of Crime, HMSO, London, UK

Houpis, G., Littlechild, M., and Gifford, S., (2001). "The Police Funding Formula: Does it Reflect London's Crime Management Needs?" Public Money and Management. Oct/Dec, 27-34.

Lovell, C. A. K., Richardson, S., Travers, P., Wood., L. L. (1994). in W. Eichorn (Ed.) Resources and Functionings: A New View of Inequality in Australia, Models and Measurement of Welfare and Inequality, Springer, Berlin.

Miller, T,. Chen, M and Rossman, S. (1993). "Victim Costs of Violent Crime and Resulting Injuries.” Heath Affairs, Winter. 12(40), 186-97. 
Nyhan, R. C. and L. M. Martin. (1999). "Assessing the Performance of Municipal Police Service Using Data Envelopment Analysis: An Exploratory Study," State and Local Government Review. 31, 18-30.

O'Connell, P. E. (2001). Using Performance Data for Accountability: The New York City Police Department's CompStat Model of Police Management, The Pricewaterhouse Coopers Endowment for The Business of Government, Iona College, USA.

Public Services Productivity Panel. (PSPP) (2000). Improving Police Performance, H. M Treasury, London, UK.

Steering Committee for the Review of Commonwealth/State Service Provision (SCRCSSP). (2000). Report on Government Service Provision 2000, Ausinfo, Canberra, Australia.

Stephens, M. (1994). "Care and control: The future of British policing." Policing and Society. 4, 237-251.

Sullivan, R. R. (1998). "The Politics of British Policing in the Thatcher/Major State." The Howard Journal. 37, 306-318.

Sun, S. (2002). "Measuring the Relative Efficiency of Police Precincts using Data Envelopment Analysis." Socio-Economic Planning Sciences, 36, 51-71.

The Royal Canadian Mounted Police. (RCMP). 2000, A Report on Plans and Priorities for 2000/2001, Canada.

Thanassoulis, E. (1995). "Assessing Police Forces in England and Wales using Data Envelopment Analysis.” European Journal of Operational Research, 87, 641657.

Votey, H. L. and Phillips, L. (1972). "Police Effectiveness and the Production Function for Law Enforcement," Journal of Legal Studies. 423-36. 
Table 1

Basic Command Unit Summary Statistics

\begin{tabular}{|c|c|c|c|c|c|}
\hline \multirow{2}{*}{ Inputs } & \multirow[t]{2}{*}{ Minimum } & \multirow[t]{2}{*}{ Maximum } & \multicolumn{2}{|c|}{ Mean Std. Deviation } & \multirow[t]{2}{*}{ Variance } \\
\hline & & & & & \\
\hline $\mathrm{X} 1$ & 173.00 & 8645.00 & 1877.03 & 1449.03 & 2099708.04 \\
\hline $\mathrm{X} 2$ & 13.00 & 536.00 & 121.82 & 85.94 & 7386.733 \\
\hline X3 & 1.00 & 4160.00 & 305.53 & 510.68 & 260798.66 \\
\hline X4 & 81.00 & 6543.00 & 1381.30 & 980.90 & 962176.95 \\
\hline X5 & 61.00 & 4912.00 & 1157.06 & 842.57 & 709939.64 \\
\hline X6 & 210.00 & 6964.00 & 2096.79 & 1229.45 & 1511549.88 \\
\hline \multicolumn{6}{|c|}{ Outputs } \\
\hline Y1 & 168.00 & 3756.00 & 1138.57 & 593.49 & 352231.28 \\
\hline Y2 & 7.00 & 262.00 & 65.27 & 36.89 & 1361.12 \\
\hline Y3 & 1.00 & 318.00 & 54.26 & 56.05 & 3142.15 \\
\hline Y4 & 9.00 & 632.00 & 198.75 & 120.28 & 14468.26 \\
\hline Y5 & 10.00 & 494.00 & 141.74 & 85.72 & 7348.54 \\
\hline Y6 & 13.00 & 562.00 & 114.04 & 82.64 & 6830.89 \\
\hline
\end{tabular}


Table 2.

Basic Command Unit (BCU) and Overall Mean

Police Force Efficiency Scores

\begin{tabular}{|c|c|c|c|c|c|c|c|}
\hline & $\begin{array}{c}\text { BCU } \\
\text { No. }\end{array}$ & $\begin{array}{c}\text { Min } \\
\text { BCU } \\
\text { SODF }\end{array}$ & $\begin{array}{c}\text { Max } \\
\text { BCU } \\
\text { SODF }\end{array}$ & $\begin{array}{l}\text { Mean } \\
\text { SODF }\end{array}$ & $\begin{array}{l}\text { Min } \\
\text { BCU } \\
\text { PTE }\end{array}$ & $\begin{array}{l}\text { Max } \\
\text { BCU } \\
\text { PTE } \\
\end{array}$ & $\begin{array}{c}\text { Mean } \\
\text { PTE }\end{array}$ \\
\hline 1. Avon and Somerset & 8 & 63.00 & 86.35 & 75.21 & 69.60 & 100.00 & 83.84 \\
\hline 2. Bedfordshire & 3 & 64.64 & 94.52 & 83.62 & 88.28 & 100.00 & 93.74 \\
\hline 3. Cambridgeshire & 3 & 77.20 & 99.98 & 89.65 & 86.39 & 100.00 & 95.46 \\
\hline 4. Cheshire & 6 & 78.31 & 96.37 & 87.41 & 84.89 & 100.00 & 96.55 \\
\hline 5. Cleveland & 4 & 63.96 & 91.13 & 76.26 & 78.36 & 100.00 & 94.59 \\
\hline 6. Cumbria & 3 & 75.92 & 97.20 & 84.76 & 100.00 & 100.00 & 100.00 \\
\hline 7. Derbyshire & 4 & 75.29 & 94.58 & 89.11 & 100.00 & 100.00 & 100.00 \\
\hline 8. Devon \& Cornwall & 16 & 74.54 & 99.25 & 89.68 & 79.97 & 100.00 & 98.60 \\
\hline 9. Dorset & 4 & 61.94 & 92.84 & 73.49 & 69.87 & 90.07 & 79.65 \\
\hline 10. Durham & 6 & 90.30 & 99.99 & 94.05 & 99.88 & 100.00 & 99.98 \\
\hline 11. Essex & 9 & 75.28 & 92.62 & 83.46 & 73.02 & 100.00 & 94.18 \\
\hline 12. Glot & 3 & 93.05 & 99.36 & 95.34 & 94.52 & 100.00 & 8.17 \\
\hline 13. Gre & 11 & 79.90 & 95.32 & 89.05 & 89.86 & 100.00 & 7.81 \\
\hline 14. Ham & 12 & 79.07 & 99.29 & 87 & 94.30 & 100.00 & 99.00 \\
\hline 15. Hert & 9 & 39.21 & 97.19 & 81. & 46.24 & 100.00 & 86.36 \\
\hline 16. Humb & 4 & 69.81 & 88.73 & 79 & 70.72 & 100.00 & 3.37 \\
\hline 17. Kent & 9 & 72.34 & 99.03 & 90 & 84.88 & 100.00 & 95.80 \\
\hline 18. Lanca & 6 & 80.72 & 97.25 & 89.55 & 91.52 & 100.00 & 97.72 \\
\hline 19. Leic & 5 & 82.78 & 97.86 & 90. & 85.79 & 100.00 & 94.95 \\
\hline 20. Lince & 3 & 91.05 & 97.59 & 95.12 & 91.71 & 100.00 & 93.73 \\
\hline 21. Mers & 11 & 71.87 & 96.40 & 85.22 & 79.31 & 100.00 & 92.91 \\
\hline 22. Metr & 32 & 45.14 & 99.57 & 74.75 & 43.86 & 100.00 & 73.36 \\
\hline 23. Nor & 3 & 79.77 & 91.41 & 86.55 & 83.35 & 89.41 & 86.16 \\
\hline 24 Nort & 4 & 82.98 & 98.88 & 94.55 & 100.00 & 100.00 & 100.00 \\
\hline 25. Nort & 15 & 79.29 & 99.20 & 90.94 & 77.89 & 100.00 & 95.18 \\
\hline 26. North Yorkshire & 3 & 86.79 & 99.39 & 95.16 & 100.00 & 100.00 & 100.00 \\
\hline 27. Nottinghamshire & 5 & 64.52 & 88.82 & 77.86 & 89.96 & 100.00 & 96.94 \\
\hline 28. South Yorkshire & 11 & 83.00 & 98.74 & 88.72 & 89.29 & 100.00 & 95.92 \\
\hline 29. Staffordshire & 4 & 52.49 & 77.45 & 67.44 & 66.64 & 100.00 & 89.03 \\
\hline 30. Suffolk & 3 & 84.74 & 98.10 & 93.98 & 100.00 & 100.00 & 100.00 \\
\hline 31. Surrey & 7 & 45.99 & 80.64 & 67.98 & 48.88 & 100.00 & 78.49 \\
\hline 32. Sussex & 8 & 63.58 & 81.82 & 73.79 & 67.69 & 100.00 & 88.09 \\
\hline 33. Thames Valley & 10 & 68.32 & 95.81 & 82.09 & 75.68 & 100.00 & 87.14 \\
\hline 34. Warwickshire & 2 & 74.30 & 87.83 & 81.07 & 82.58 & 84.75 & 83.66 \\
\hline 35. West Mercia & 6 & 80.98 & 98.02 & 85.32 & 81.04 & 100.00 & 90.43 \\
\hline 36. West Midlands & 21 & 73.18 & 99.87 & 91.41 & 85.88 & 100.00 & 97.75 \\
\hline 37. West Yorkshire & 3 & 59.76 & 99.85 & 91.11 & 83.60 & 100.00 & 97.30 \\
\hline 38. Wiltshire & 3 & 61.63 & 92.82 & 79.70 & 91.84 & 100.00 & 96.88 \\
\hline
\end{tabular}


Table 3.

Top and Bottom 20 Basic Command Unit SODF Efficiency Scores

\begin{tabular}{|c|c|c|}
\hline Force Name & Basic Command Unit & \\
\hline 1 Durham & Easington & 99.99 \\
\hline 2 Cambridgeshire & Southern & 99.98 \\
\hline 3 West Midlands & $\begin{array}{l}\text { F3 - Soho / Handsworth / Sandwell / Perry Barr } \\
\text { / Aston (part) }\end{array}$ & 99.87 \\
\hline 4 West Yorkshire & Dewsbury & 99.85 \\
\hline 5 West Midlands & J1 - Brierley Hill / Dudley / Sedgeley / Gornal & 99.76 \\
\hline 6 Durham & Darlington & 99.68 \\
\hline 7 Metropolitan Police & Lambeth & 99.57 \\
\hline 8 North Yorkshire & Eastern & 99.39 \\
\hline 9 Gloucestershire & Forest and Gloucester & 99.36 \\
\hline 10 North Yorkshire & Central & 99.31 \\
\hline 11 Hampshire & North East Hampshire & 99.29 \\
\hline 12 Devon \& Cornwall & Torridge & 99.25 \\
\hline 13 Northumbria & Newcastle Central & 99.20 \\
\hline 14 Metropolitan Police & Haringey & 99.17 \\
\hline 15 Suffolk & Southern & 99.11 \\
\hline 16 Metropolitan Police & Hackney & 99.10 \\
\hline 17 Kent & North Kent & 99.03 \\
\hline 18 Northamptonshire & Western & 98.88 \\
\hline 19 South Yorkshire & Rotherham East & 98.74 \\
\hline 20 Lancashire & Pennine & 98.72 \\
\hline Force Name & Basic Command Unit & \\
\hline 274 Sussex & Senlac & 63.58 \\
\hline 275 Avon and Somerset & North Bristol & 63.44 \\
\hline 276 Avon and Somerset & North Somerset & 63.00 \\
\hline 277 Metropolitan Police & Kensington and Chelsea & 62.51 \\
\hline 278 Metropolitan Police & Sutton & 62.16 \\
\hline 279 Wiltshire & Swindon (D) & 61.63 \\
\hline 280 Metropolitan Police & Redbridge & 61.46 \\
\hline 281 Metropolitan Police & Kingston-upon-Thames & 61.18 \\
\hline 282 Dorset & Bournemouth & 60.94 \\
\hline 283 Hertfordshire & Hertsmere & 60.76 \\
\hline 284 Metropolitan Police & Richmond-upon-Thames & 59.98 \\
\hline 285 West Yorkshire & Weetwood & 59.76 \\
\hline 286 Metropolitan Police & Brent & 59.38 \\
\hline 287 Metropolitan Police & Merton & 57.09 \\
\hline 288 Staffordshire & North Staffordshire & 52.49 \\
\hline 289 Metropolitan Police & Harrow & 51.82 \\
\hline 290 Metropolitan Police & Bromley & 51.25 \\
\hline 291 Surrey & Spellthorne & 45.99 \\
\hline 292 Metropolitan Police & Hillingdon & 45.14 \\
\hline 293 Hertfordshire & Broxbourne & 39.21 \\
\hline
\end{tabular}


Figure 1.

Police Force's Basic Command Unit SODF Efficiency Scores.

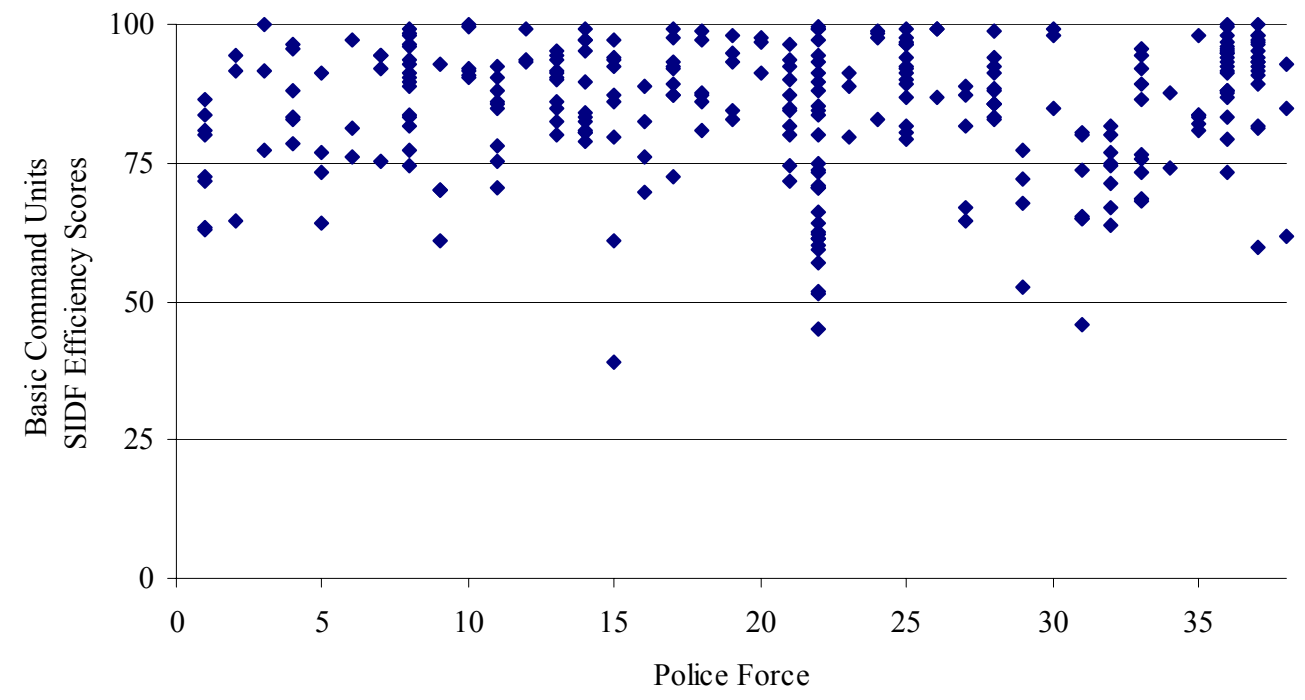

Figure 2.

Police Force's Basic Command Unit PTE Efficiency Scores.

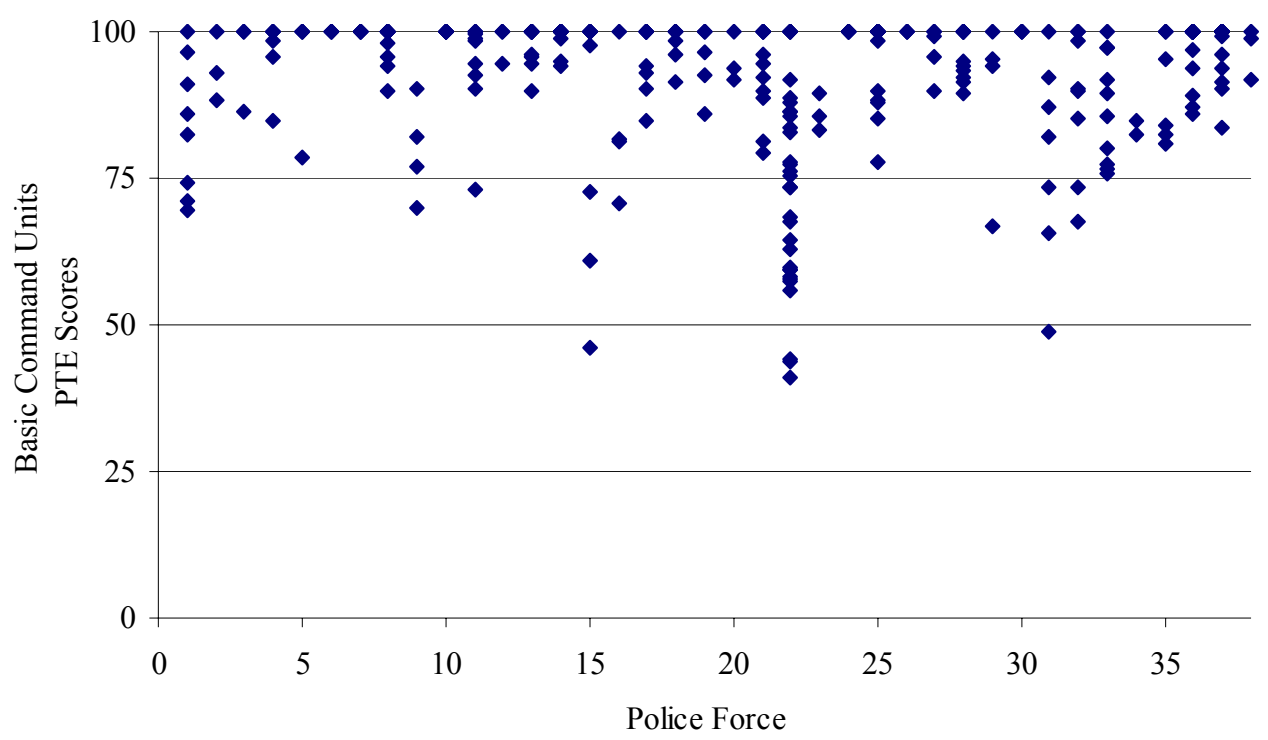


Figure 3.

PTE and SODF Basic Command Unit Efficiency Scores.

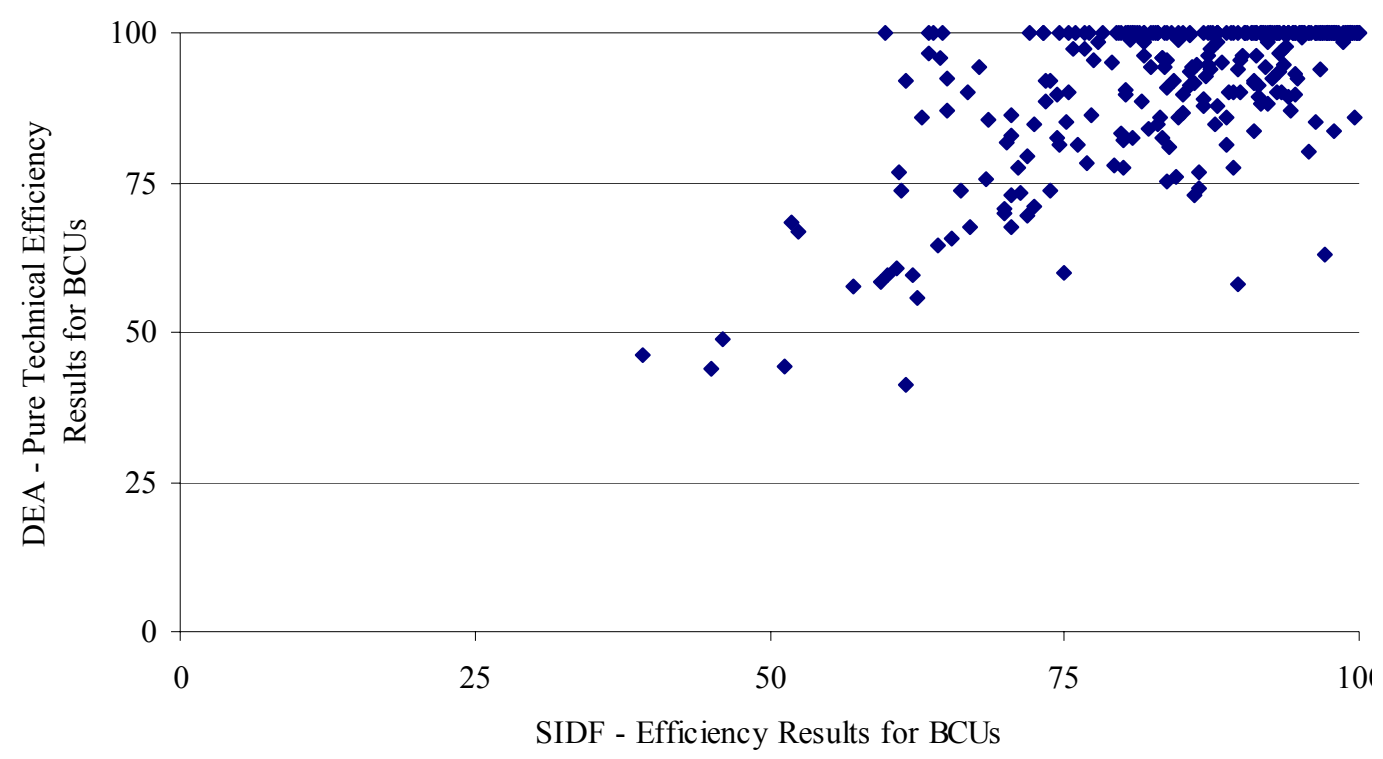

Figure 4.

Pure Technical Efficiency and Crime Incidences Relationship

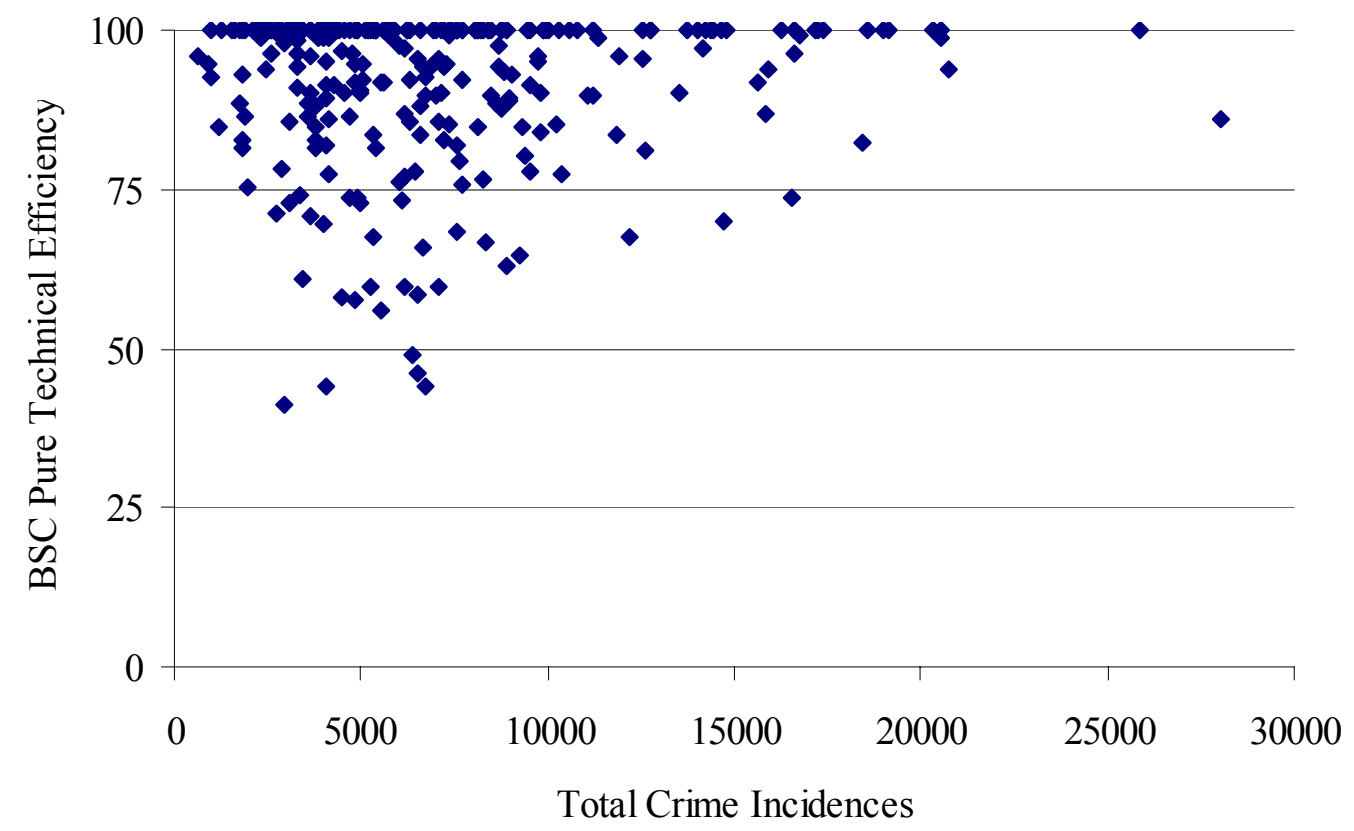


Figure 5.

Scale Efficiency and Crime Incidences Relationship

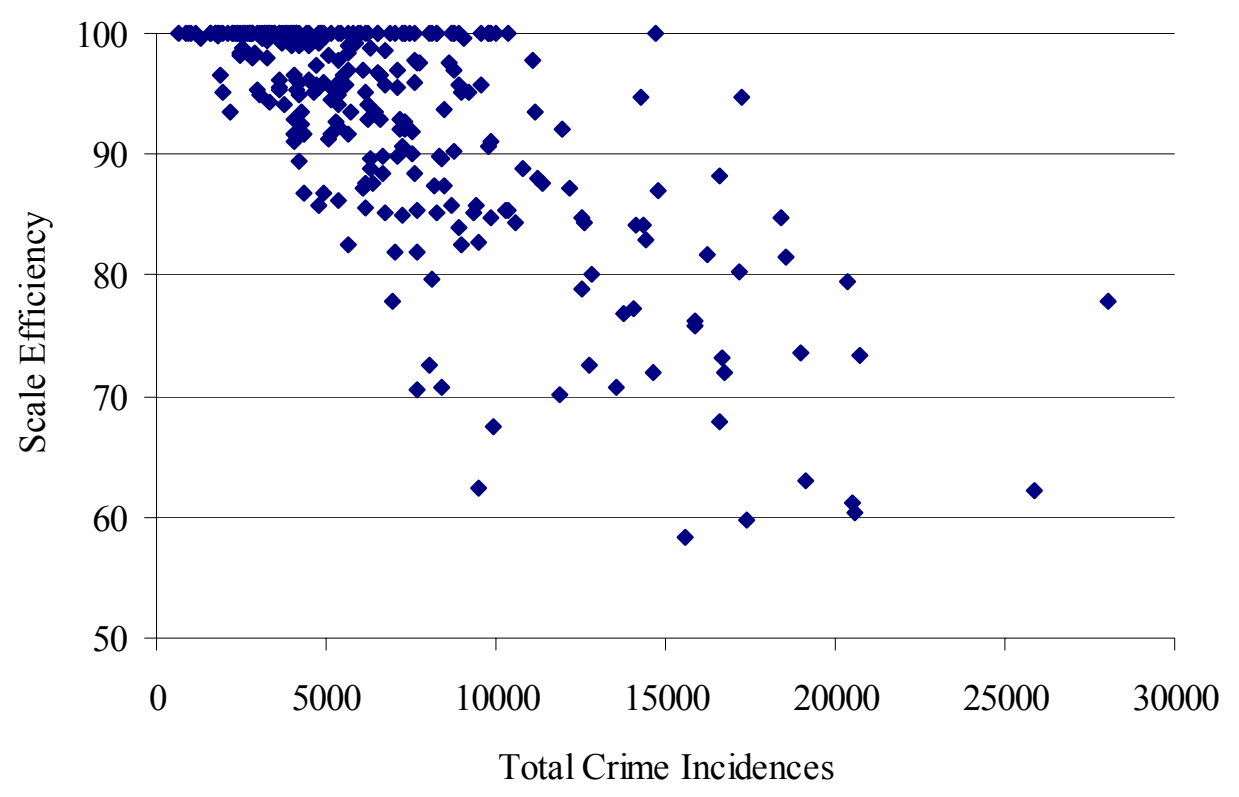

